\title{
On the possibility of magneto-structural correlations: Detailed studies of di-nickel carboxylate complexes
}

\author{
James P. S. Walsh, ${ }^{\dagger}$ Stephen Sproules ${ }^{\dagger \dagger}{ }^{\ddagger}$ Nicholas F. Chilton,${ }^{\dagger}$ Anne-Laure Barra, ${ }^{\S}$ Grigore A. Timco, ${ }^{\dagger}$ \\ David Collison, ${ }^{\dagger *}$ Eric J. L. McInnes ${ }^{\dagger}$ and Richard E. P. Winpenny ${ }^{\dagger}$ \\ 'School of Chemistry and Photon Science Institute, University of Manchester, Manchester, M13 9PL, United Kingdom. \\ ${ }^{\ddagger}$ WestCHEM, School of Chemistry, University of Glasgow, Glasgow, G12 8QQ, United Kingdom. \\ ${ }^{\S}$ Laboratoire National des Champs Magnétiques Intenses, 25, rue des Martyrs, B.P. 166, 38042 Grenoble Cedex, France. \\ *david.collison@manchester.ac.uk
}

\begin{abstract}
A series of water-bridged dinickel complexes of the general formula $\left[\mathrm{Ni}_{2}\left(\mu_{2}-\mathrm{OH}_{2}\right)\left(\mu_{2}-\right.\right.$ $\left.\left.\mathrm{O}_{2} \mathrm{C}^{t} \mathrm{Bu}\right)_{2}\left(\mathrm{O}_{2} \mathrm{C}^{t} \mathrm{Bu}\right)_{2}(\mathrm{~L})\left(\mathrm{L}^{\prime}\right)\right]\left(\mathrm{L}=\mathrm{HO}_{2} \mathrm{C}^{t} \mathrm{Bu}, \mathrm{L}^{\prime}=\mathrm{HO}_{2} \mathrm{C}^{t} \mathrm{Bu}\right.$ (1), pyridine (2), 3-methylpyridine (4); $\mathrm{L}=\mathrm{L}^{\prime}$ = pyridine (3), 3-methylpyridine (5)) has been synthesized and structurally characterized by X-ray crystallography. The magnetic properties have been probed by magnetometry and EPR spectroscopy, and detailed measurements show that the axial zero-field splitting, $D$, of the nickel(II) ions is on the same order as the isotropic exchange interaction, $J$, between the nickel sites. The isotropic exchange interaction can be related to the angle between the nickel centers and the bridging water molecule, while the magnitude of $D$ can be related to the coordination sphere at the nickel sites.
\end{abstract}

\section{Introduction}

With growing interest in the use of molecular nanomagnets in applications such as quantum computing ${ }^{1}$ and magnetocaloric refrigeration, ${ }^{2}$ it is becoming increasingly important to be able to relate the magnetic properties of molecular nanomagnets to their chemical structure. For spin-only systems, where orbital angular momentum is quenched, there has been some success ${ }^{3-6}$ in relating the form of the exchange interaction (either ferro- or antiferromagnetic) to structural parameters, and such studies often use the term magneto-structural correlations to describe these relationships.

An important question has been which structural parameter to use in these correlations. Two of the most commonly encountered parameters are the bridging bond angle, as in Hatfield's famous correlation for hydroxide-bridged copper(II) dimers, ${ }^{7}$ and the bond distance between the metal and the bridge, as used by Gorun and Lippard, ${ }^{5}$ developed by Güdel and Weihe, ${ }^{8}$ and later Christou and co-workers. ${ }^{9,10}$ These correlations have been of huge importance in developing the area of molecular magnetism, but they were all derived during a time when chemists generally only measured variable temperature susceptibility as a magnetic observable, and when the only terms in the spin Hamiltonian were the Zeeman term and the exchange interaction. This modeling approach makes the assumption that the exchange interaction, $J$, is dominant, and is often called the "strong-exchange" limit, or the "giant spin approximation" (GSA).

Nowadays, encouraged by friendly physicists, our physical measurements are more comprehensive. Perhaps most significantly, groups now routinely report field-dependent magnetisation alongside variable temperature susceptibility, and there is also now significant use of inelastic neutron scattering (INS), largely driven by Güdel in the first instance. ${ }^{11}$ The number of parameters used in the spin Hamiltonian has also increased, primarily due to the realization that the anisotropy of the single ions is frequently of significance in determining physical behaviour. Recent work has also sug- gested that the form of the exchange interactions used is also vital, e.g. anisotropic exchange in $\left\{\mathrm{Cr}_{7} \mathrm{M}\right\}$ rings ${ }^{12}$ and anti-symmetric exchange within $\left\{\mathrm{Ru}_{2} \mathrm{M}\right\}$ triangles. ${ }^{13}$

A major goal in the field of single-molecule magnets (SMMs) is to increase the size of the barrier to magnetic relaxation. The height of this barrier depends upon both the total ground state spin of the molecule, $S$, and its axial anisotropy, $D$, according to the following equation:

$$
\Delta U_{\mathrm{eff}}=D S^{2}
$$

Given the apparent dominance of the spin term in this relationship, much of the early effort in the field was spent trying to maximize $S$. However, it was soon realized that the anisotropy could not be neglected, and that even a huge ground state spin could result in a poor SMM if the anisotropy was negligible. ${ }^{14}$ This has encouraged a shift towards the use of ions with a large intrinsic anisotropy, since these are more likely to translate to a large $D$ in clusters (the cluster $D$ approximates to a tensor sum of the single ion anisotropy terms). Lanthanides have proven to be very promising in this regard, with many of the recent energy barrier record holders utilizing their high intrinsic spin and anisotropy terms. ${ }^{15}$

Similar success might be possible using transition metal elements, with the added advantage of a more diverse chemistry and a significantly greater natural abundance. Unfortunately, the most anisotropic of the $d$-block ions are, by definition, not well-described using spinonly models, ${ }^{16}$ and certainly not with models based on the GSA. There is therefore a real need for chemists and physicists to devote more research towards understanding exactly which factors dictate the exchange interactions between anisotropic ions. The question arises: which, if any, magnetic parameter should be used within these correlations? This is especially important, as it dictates the Hamiltonian used to fit the data.

A well-cited magneto-structural study by Halcrow et al. reveals a 
linear relationship between isotropic exchange, $J$, and the $\mathrm{Ni}-\mathrm{O}-\mathrm{Ni}$ angle in oxo-bridged nickel(II) cubanes, ${ }^{9}$ but does so using only the temperature-dependent susceptibility, and under the assumption that the effect of the zero-field splitting (ZFS) is negligible at higher temperatures, i.e. it implicitly uses the GSA. More recent work by Hill and co-workers has revealed that the magnitude of the ZFS in nickel(II) is actually non-negligible in these compounds. ${ }^{17} \mathrm{~A}$ similar correlation of $J$ with $\mathrm{Ni}-\mathrm{O}-\mathrm{Ni}$ angle has also been proposed by Thompson and co-workers. ${ }^{18}$

Here we report a magnetostructural study on a family of five structurally related nickel(II) dimetallics where the zero-field splitting is on the same order of magnitude as the exchange interaction between the ions. The aim is to examine whether we can still find similar magnetostructural correlations when a more complex Hamiltonian is required, and where more data are available.

\section{Experimental Section}

\section{Synthesis}

All reagents, metal salts and ligands were used as obtained from Sigma-Aldrich. $\quad\left[\mathrm{Ni}_{2}\left(\mu_{2}-\mathrm{OH}_{2}\right)\left(\mu_{2}-\mathrm{O}_{2} \mathrm{C}^{t} \mathrm{Bu}\right)_{2}\left(\mathrm{O}_{2} \mathrm{C}^{t} \mathrm{Bu}\right)_{2}\left(\mathrm{HO}_{2} \mathrm{C}^{t} \mathrm{Bu}\right)_{4}\right]$ (1) was synthesized following a literature procedure, ${ }^{19}$ whereas $\mathbf{2}$ and $\mathbf{3}$ were prepared by modification of published methods. ${ }^{20}$

$\left[\mathrm{Ni}_{2}\left(\mu_{2}-\mathrm{OH}_{2}\right)\left(\mu_{2}-\mathrm{O}_{2} \mathrm{C}^{t} \mathrm{Bu}\right)_{2}\left(\mathrm{O}_{2} \mathrm{C}^{t} \mathrm{Bu}\right)_{2}\left(\mathrm{HO}_{2} \mathrm{C}^{t} \mathrm{Bu}\right)_{2}\left(\mathrm{C}_{5} \mathrm{H}_{5} \mathrm{~N}\right)_{2}\right]$ (2) A light green solution of $\mathbf{1}(1.00 \mathrm{~g}, 1.10 \mathrm{mmol})$ in $\mathrm{Et}_{2} \mathrm{O}(10 \mathrm{~mL})$ was treated with pyridine $(0.18 \mathrm{~mL}, 2.32 \mathrm{mmol})$. After $1 \mathrm{~h}$ stirring at ambient temperature, $\mathrm{MeCN}(4 \mathrm{~mL})$ was added and the solution left to stand overnight, after which time diffraction quality crystals had formed. These were collected by filtration, washed with cold MeCN

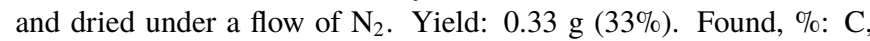
53.11; H, 7.79; N, 3.36. Calc. for $\mathrm{C}_{40} \mathrm{H}_{68} \mathrm{~N}_{2} \mathrm{Ni}_{2} \mathrm{O}_{13}, \mathrm{C}, 53.24 ; \mathrm{H}$, $7.60 ; \mathrm{N}, 3.10$.

$\left[\mathrm{Ni}_{2}\left(\mu_{2}-\mathrm{OH}_{2}\right)\left(\mu_{2}-\mathrm{O}_{2} \mathrm{C}^{t} \mathrm{Bu}\right)_{2}\left(\mathrm{O}_{2} \mathrm{C}^{t} \mathrm{Bu}\right)_{2}\left(\mathrm{C}_{5} \mathrm{H}_{5} \mathrm{~N}\right)_{4}\right](3)$

Same procedure as described for 2 using excess pyridine $(0.50 \mathrm{~mL}$, $6.45 \mathrm{mmol})$. Yield: $0.41 \mathrm{~g}$ (44\%). Found, \%: C, 55.98; H, 6.93; N, 6.43. Calc. for $\mathrm{C}_{40} \mathrm{H}_{58} \mathrm{~N}_{4} \mathrm{Ni}_{2} \mathrm{O}_{9}, \mathrm{C}, 56.10 ; \mathrm{H}, 6.83 ; \mathrm{N}, 6.54$.

$\left[\mathrm{Ni}_{2}\left(\mu_{2}-\mathrm{OH}_{2}\right)\left(\boldsymbol{\mu}_{2}-\mathrm{O}_{2} \mathrm{C}^{t} \mathrm{Bu}\right)_{2}\left(\mathrm{O}_{2} \mathrm{C}^{t} \mathrm{Bu}\right)_{2}\left(\mathrm{HO}_{2} \mathrm{C}^{t} \mathrm{Bu}_{2}\left(\mathrm{CH}_{3} \mathrm{C}_{5} \mathrm{H}_{4} \mathrm{~N}\right)_{2}\right]\right.$ (4) Same procedure as described for 2 using 3-methylpyridine $(0.20 \mathrm{~mL}$, $2.26 \mathrm{mmol})$. Yield: $0.30 \mathrm{~g}(29 \%)$. Found, \%: C, 54.20; H, 7.86; N, 2.91. Calc. for $\mathrm{C}_{42} \mathrm{H}_{72} \mathrm{~N}_{2} \mathrm{Ni}_{2} \mathrm{O}_{13}, \mathrm{C}, 54.22 ; \mathrm{H}, 7.80 ; \mathrm{N}, 3.01$.

$\left[\mathrm{Ni}_{2}\left(\mu_{2}-\mathrm{OH}_{2}\right)\left(\mu_{2}-\mathrm{O}_{2} \mathrm{C}^{t} \mathrm{Bu}\right)_{2}\left(\mathrm{O}_{2} \mathrm{C}^{t} \mathrm{Bu}\right)_{2}\left(\mathrm{CH}_{3} \mathrm{C}_{5} \mathrm{H}_{4} \mathrm{~N}\right)_{4}\right]$ (5)

Same procedure as described for $\mathbf{2}$ using excess 3-methylpyridine (0.50 mL, $5.65 \mathrm{mmol})$. Yield: $0.30 \mathrm{~g} \mathrm{(29 \% ).} \mathrm{Found,} \mathrm{\% :} \mathrm{C,} \mathrm{57.94;} \mathrm{H,}$ 7.51; N, 6.06. Calc. for $\mathrm{C}_{44} \mathrm{H}_{66} \mathrm{~N}_{4} \mathrm{Ni}_{2} \mathrm{O}_{9}, \mathrm{C}, 57.92 ; \mathrm{H}, 7.44 ; \mathrm{N}, 6.14$.

$\left[\mathrm{Mg}_{2-\boldsymbol{x}} \mathrm{Ni}_{\boldsymbol{x}}\left(\boldsymbol{\mu}_{\mathbf{2}}-\mathrm{OH}_{\mathbf{2}}\right)\left(\boldsymbol{\mu}_{\mathbf{2}}-\mathrm{O}_{\mathbf{2}} \mathrm{C}^{t} \mathrm{Bu}\right)_{\mathbf{2}}\left(\mathrm{O}_{\mathbf{2}} \mathrm{C}^{t} \mathrm{Bu}\right)_{\mathbf{2}}\left(\mathrm{HO}_{\mathbf{2}} \mathrm{C}^{t} \mathrm{Bu}\right)_{\mathbf{4}}\right](\mathbf{6})$ $4 \mathrm{MgCO}_{3} \cdot \mathrm{Mg}(\mathrm{OH})_{2} \cdot 4 \mathrm{H}_{2} \mathrm{O}(8.00 \mathrm{~g}, 17.1 \mathrm{mmol}), 2 \mathrm{NiCO}_{3} \cdot 3 \mathrm{Ni}(\mathrm{OH})_{2}$. $4 \mathrm{H}_{2} \mathrm{O}(0.5285 \mathrm{~g}, 0.8994 \mathrm{mmol})$, and pivalic acid (40.0 g, $\left.39.2 \mathrm{mmol}\right)$ were stirred under reflux $\left(160{ }^{\circ} \mathrm{C}\right)$ for $24 \mathrm{hr}$. The mixture was then cooled to room temperature and dissolved fully in an excess of diethyl ether $(200 \mathrm{~mL})$. MeCN $(30 \mathrm{~mL})$ was added with thorough stirring and the solution was left to stand partially open to allow slow evaporation. Large single crystals formed after two days. Yield: $6.32 \mathrm{~g}$ (39.9\%). Found, \%: C, 54.47; H, 8.61; Mg, 5.65; Ni, 0.58. Calc. for
$\mathrm{C}_{40} \mathrm{H}_{78} \mathrm{Mg}_{1.95} \mathrm{Ni}_{0.05} \mathrm{O}_{17}, \mathrm{C}, 54.40 ; \mathrm{H}, 8.90 ; \mathrm{Mg}, 5.23 ; \mathrm{Ni}, 0.66$.

\section{X-ray Crystallography}

The single crystal structures of $\mathbf{1}$ and $\mathbf{2}$ have been reported previously. ${ }^{19,20}$ Single crystals of 3-6 were mounted in the nitrogen cold stream of an Oxford Diffraction XCalibur 2 diffractometer. Graphite monochromated Mo-K $\alpha$ radiation $(\lambda=0.71073 \AA)$ was used throughout. Final cell constants were obtained from least squares fits of all measured reflections. The structures were solved by direct methods using SHELXS-97. ${ }^{21}$ Each structure was completed by iterative cycles of $\Delta F$-syntheses and full-matrix least-squares refinement. All non-H atoms were refined anisotropically. Difference Fourier syntheses were employed in positioning idealized methyl-hydrogen atoms, which were assigned isotropic thermal parameters $[U(\mathrm{H})=$ $1.5 U_{\mathrm{eq}}(\mathrm{C})$ ], and allowed to ride on their parent C-atoms [C-H $\left.0.93 \AA\right]$. Some pivalate groups exhibited rotational disorder. This was modeled by allowing for two conformations of the $t$-butyl group and refining their occupancy factors. All refinements were against $F^{2}$ and used SHELXL- 97. ${ }^{21}$ Crystallographic data are collected in Table 1. CCDC reference numbers: 926884-926886 (3 to 5) and 999472 (6).

\section{Physical Measurements}

Electronic absorption spectra were collected on a Perkin-Elmer Lambda 1050 spectrophotometer. IR spectra of neat powders were recorded using a Thermo Scientific Nicolet iS5 FTIR spectrometer equipped with an iD5 ATR. Variable temperature (2-300 K) magnetic susceptibility measurements were recorded in a $0.1 \mathrm{~T}$ magnetic field on a SQUID magnetometer (Quantum Design MPMS-XL). The experimental magnetic susceptibility data were corrected for underlying diamagnetism using tabulated Pascal's constants, and the simulations of both magnetisation and susceptibility performed using PHI. ${ }^{22} \mathrm{Q}-$ band EPR data were collected on a Bruker EMX spectrometer, and high-frequency, high-field EPR spectra were recorded at the LNCMICNRS at Grenoble on a home-built spectrometer. ${ }^{23}$ EPR spectra were simulated using EasySpin. ${ }^{24}$ Analytical data were obtained by the microanalytical service of The University of Manchester.

\section{Computational Details}

All CASSCF calculations were performed with MOLCAS $7.8^{25}$ using the RASSCF, RASSI and SINGLE_ANISO modules. In all cases the ANO-RCC basis sets were used, where the metal ion of interest was treated with TZVP quality, the first coordination sphere (and bridging water hydrogen atoms) were treated with VDZP quality, and all other atoms were treated with VDZ quality. The two electron integrals were Cholesky decomposed with the default settings.

\section{Results and Discussion}

\section{Synthesis and Characterization}

The entry point for this series is $\left[\mathrm{Ni}_{2}\left(\mu_{2}-\mathrm{OH}_{2}\right)\left(\mu_{2}-\mathrm{O}_{2} \mathrm{C}^{t} \mathrm{Bu}\right)_{2}\right.$ $\left.\left(\mathrm{O}_{2} \mathrm{C}^{t} \mathrm{Bu}\right)_{2}\left(\mathrm{HO}_{2} \mathrm{C}^{t} \mathrm{Bu}\right)_{4}\right](\mathbf{1})$, whose preparation involves heating nickel carbonate or nickel hydroxide in pivalic acid. ${ }^{19}$ The compound contains two nickel(II) ions bridged by one water and two pivalate ligands (Figure 1). ${ }^{26}$ Structures of this type are well known for nickel and a host of other divalent metal ions. ${ }^{27}$ In addition to the bridging pivalates, each metal also bears a monodentate pivalate ligand that 


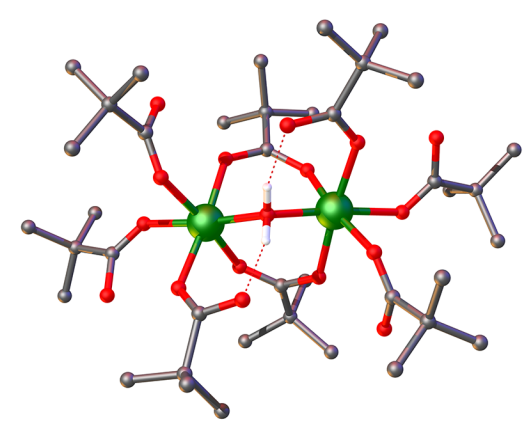

1

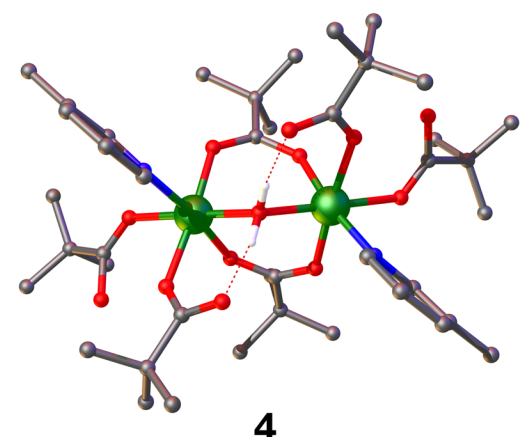

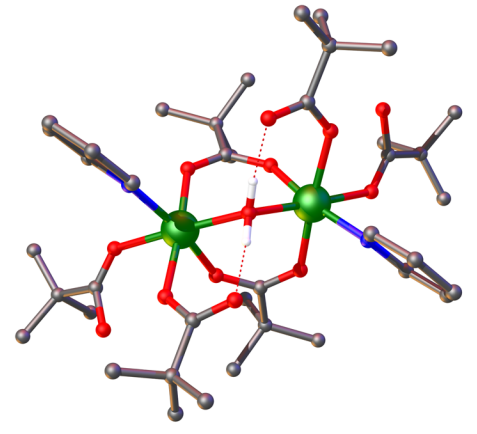

2

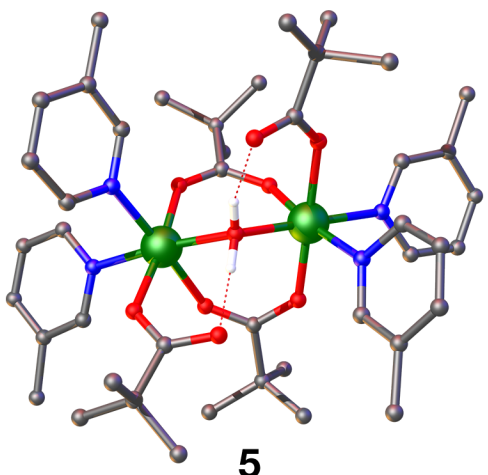

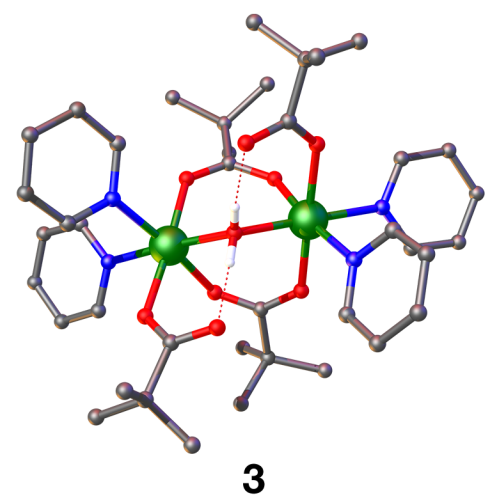

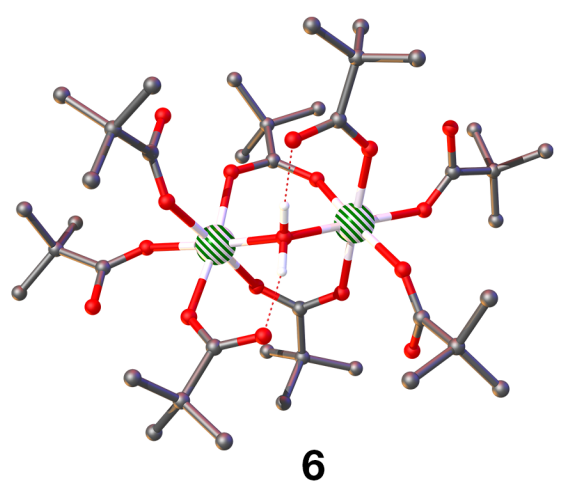

Figure 1. Structure of the neutral complexes in the crystal state. Data for $\mathbf{1}$ and $\mathbf{2}$ from Refs. 26 and 20 , respectively. All hydrogens omitted with the exception of those found crystallographically on the bridging water. Hydrogen bonds are indicated by dashed lines.

provides a stabilizing hydrogen bond at $\sim 2.5 \AA$ to the bridging water molecule. The coordination sphere of each metal ion is completed by two pivalic acid groups, and the complex has an overall neutral charge.

Substitution of the terminal pivalic acid groups in $\mathbf{1}$ occurs in two stages. The pivalic acid cis to the bridging water, which is more labile than its trans counterpart, departs first. Compounds 2 and $\mathbf{4}$ are generated by treatment with two equivalents of pyridine and 3methylpyridine, respectively, in 30\% yield (Figure 1). Further substitution utilizes an excess of pyridine and 3-methylpyridine to afford $\mathbf{3}$ and $\mathbf{5}$, respectively, in similar yields (Figure 1).

Infrared (IR) spectra of this series do not display any terminal $v(\mathrm{OH})$ stretches from either the bridging water or pivalic acid ligands. This is due to the formation of intramolecular hydrogen bonds, with the aforementioned interaction between the bridging water and the available oxygen atom of the monodentate pivalate ligands, and also between the pivalic acid protons and their neighboring monodentate and bridging pivalate groups. This results in a weakening of the O-H bond, shifting it to the $v(\mathrm{CH})$ region $\left(2800-3000 \mathrm{~cm}^{-1}\right.$; Figure $\mathrm{S} 1)$.

The change in electronic structure upon substituting pivalic acid for stronger field pyridine ligands is evident in the electronic spectra of this series (Figure 2). The low energy region $\left(<25000 \mathrm{~cm}^{-1}\right)$ shows three ligand field (LF) transitions at $\sim 9000, \sim 15000$ and $\sim 25000$ $\mathrm{cm}^{-1}$ (Table 2). This profile bears a striking resemblance to that of $\left[\mathrm{Ni}\left(\mathrm{OH}_{2}\right)_{6}\right]^{2+},{ }^{28}$ and the spectra have been interpreted assuming approximate octahedral symmetry at each $d^{8}$ ion. The lowest energy ${ }^{3} \mathrm{~A}_{1 \mathrm{~g}} \rightarrow{ }^{3} \mathrm{~T}_{2 \mathrm{~g}}$ excitation is a measure of the LF, following the trend 1 $<\mathbf{2}, \mathbf{4}<\mathbf{3}, \mathbf{5}$. The additional methyl substituent in $\mathbf{4}$ and $\mathbf{5}$ has no

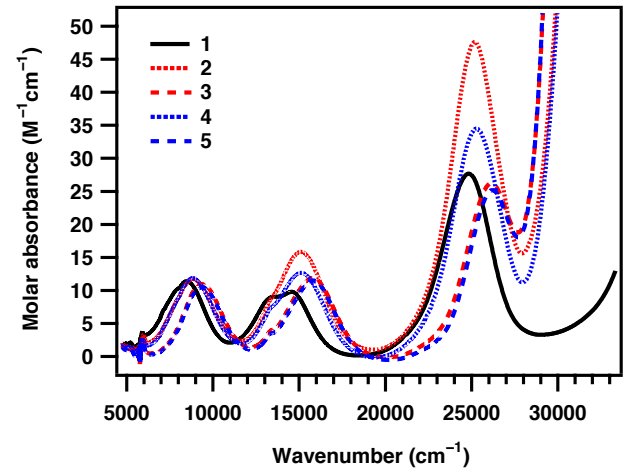

Figure 2. Electronic absorption spectra of 1-5 recorded in $\mathrm{Et}_{2} \mathrm{O}$ solutions at ambient temperature.

effect on the transition energies.

The LF splitting of 1 at $8440 \mathrm{~cm}^{-1}$ matches that of the hexaaquanickel(II) ion, ${ }^{28}$ which is not unexpected for a $\mathrm{NiO}_{6}$ coordination sphere. A uniform increase of $\sim 400-500 \mathrm{~cm}^{-1}$ is observed when the $\pi$-donating pivalic acid is replaced by a $\sigma$-donating pyridine to generate $\mathrm{NiNO}_{5}$ and $\mathrm{NiN}_{2} \mathrm{O}_{4}$ centers in $\mathbf{2}$ and $\mathbf{4}$, and $\mathbf{3}$ and $\mathbf{5}$, respectively. The two higher energy transitions are similarly shifted. Each complex also exhibits a peak that we assign as the spin-flip ${ }^{3} \mathrm{~A}_{2 \mathrm{~g}} \rightarrow{ }^{1} \mathrm{E}_{\mathrm{g}}$ excitation, whose intensity is enhanced by proximity to the spin-allowed ${ }^{3} \mathrm{~A}_{2 \mathrm{~g}} \rightarrow{ }^{3} \mathrm{~T}_{1 \mathrm{~g}}$ transition. This is most clearly seen in the spectrum of 1 where the peaks at 13350 and $14580 \mathrm{~cm}^{-1}$ appear to have the same 
Table 1. Crystallographic Data for Compounds 3-6

\begin{tabular}{|c|c|c|c|c|}
\hline Compound & 3 & 4 & 5 & 6 \\
\hline formula & $\mathrm{C}_{40} \mathrm{H}_{58} \mathrm{~N}_{4} \mathrm{Ni}_{2} \mathrm{O}_{9}$ & $\mathrm{C}_{42} \mathrm{H}_{72} \mathrm{~N}_{2} \mathrm{Ni}_{2} \mathrm{O}_{13}$ & $\mathrm{C}_{44} \mathrm{H}_{66} \mathrm{~N}_{4} \mathrm{Ni}_{2} \mathrm{O}_{9} \cdot \mathrm{C}_{2} \mathrm{H}_{3} \mathrm{~N}$ & $\mathrm{C}_{40} \mathrm{H}_{78} \mathrm{Mg}_{2-x} \mathrm{Ni}_{x} \mathrm{O}_{17}$ \\
\hline $\mathrm{fw}, \mathrm{g} \mathrm{mol}^{-1}$ & 856.3 & 930.4 & 953.5 & 879.64 \\
\hline crystal system & monoclinic & monoclinic & orthorhombic & monoclinic \\
\hline space group & $P 2_{1} / c$ & $C 2 / c$ & Pna $2_{1}$ & $P 2_{1} / n$ \\
\hline$a, \AA$ & $10.7520(4)$ & $24.2188(8)$ & $20.204(1)$ & $12.0516(6)$ \\
\hline$b, \AA$ & $20.1962(5)$ & $19.6774(9)$ & $10.7563(6)$ & $19.9828(8)$ \\
\hline$c, \AA$ & $42.546(1)$ & $10.4136(5)$ & $23.1760(1)$ & $22.9732(12)$ \\
\hline$\beta,{ }^{\circ}$ & $92.358(2)$ & $98.088(4)$ & 90 & $103.790(5)$ \\
\hline$V, \AA^{3}$ & $9231.1(5)$ & 4913.4(4) & $5036.6(5)$ & $5373.1(4)$ \\
\hline$T, \mathrm{~K}$ & $100(2)$ & $100(2)$ & $150(2)$ & $150(2)$ \\
\hline $\mathrm{Z}$ & 8 & 4 & 4 & 4 \\
\hline$\rho$ calcd, $\mathrm{g} \mathrm{cm}^{-3}$ & 1.232 & 1.258 & 1.257 & 1.087 \\
\hline$\lambda, \AA / \mu, \mathrm{mm}^{-1}$ & $0.71073 / 0.867$ & $0.71073 / 0.825$ & $0.71073 / 0.802$ & $0.71073 / 0.104$ \\
\hline refl. collected / $2 \theta_{\max }$ & $36116 / 52.74$ & $9491 / 52.74$ & $12471 / 52.74$ & $17587 / 52.74$ \\
\hline unique refl. / $I>2 \sigma(I)$ & 18841 / 13977 & $5031 / 4074$ & $6920 / 5113$ & 10874 / 6792 \\
\hline no. of param. / restr. & $1064 / 23$ & $282 / 0$ & $584 / 2$ & $568 / 0$ \\
\hline$R_{1} /$ goodness of fit & $0.0598 / 1.050$ & $0.0489 / 1.050$ & $0.0569 / 1.039$ & $0.0643 / 1.029$ \\
\hline$w R_{2}(I>2 \sigma(I))$ & 0.1496 & 0.1332 & 0.1263 & 0.1415 \\
\hline residual density, e $\AA^{-3}$ & $0.91 /-0.69$ & $1.28 /-0.52$ & $0.58 /-0.84$ & $0.43 /-0.36$ \\
\hline
\end{tabular}

Table 2. Assignment of LF Transitions in $\mathbf{1}-\mathbf{5}^{a}$

\begin{tabular}{llllll} 
& $\mathbf{1}$ & $\mathbf{2}$ & $\mathbf{3}$ & $\mathbf{4}$ & $\mathbf{5}$ \\
\hline${ }^{3} \mathrm{~A}_{2 \mathrm{~g}} \rightarrow{ }^{3} \mathrm{~T}_{2 \mathrm{~g}}(\mathrm{~F})$ & 8440 & 8830 & 9380 & 8830 & 9360 \\
${ }^{3} \mathrm{~A}_{2 \mathrm{~g}} \rightarrow{ }^{1} \mathrm{E}_{\mathrm{g}}(\mathrm{D})$ & 13350 & 13380 & 13370 & 13430 & 13310 \\
${ }^{3} \mathrm{~A}_{2 \mathrm{~g}} \rightarrow{ }^{3} \mathrm{~T}_{1 \mathrm{~g}}(\mathrm{~F})$ & 14580 & 15100 & 15800 & 15120 & 15810 \\
${ }^{3} \mathrm{~A}_{2 \mathrm{~g}} \rightarrow{ }^{3} \mathrm{~T}_{1 \mathrm{~g}}(\mathrm{P})$ & 24830 & 25190 & 26160 & 25280 & 26230 \\
\hline
\end{tabular}

${ }^{a}$ Energy in $\mathrm{cm}^{-1}$.

intensity and are difficult to differentiate. However, in $\mathbf{3}$ and $\mathbf{5}$, the stronger ligand field blue shifts the spin-allowed excitation, leaving a weak shoulder to lower energy. Because this peak is essentially independent of the crystal field, it is assigned as the ${ }^{3} \mathrm{~A}_{2 \mathrm{~g}} \rightarrow{ }^{1} \mathrm{E}_{\mathrm{g}}$ transition in all five compounds.

Given that the zero-field splitting, $|D|$, of the ${ }^{3} \mathrm{~A}_{2 \mathrm{~g}}$ term is, to a first approximation, inversely proportional to the magnitude of the ligand field, we would expect this zero-field splitting to be larger in $\mathbf{2}$ and $\mathbf{4}$ than in $\mathbf{3}$ and $\mathbf{5}$, and this is indeed what is observed (vide infra). The smaller magnitude of $|D|$ in $\mathbf{1}$, despite having a ligand field strength smaller than $\mathbf{2}$ and $\mathbf{4}$, might be explained by $\mathbf{1}$ having a coordination environment $\left(\mathrm{NiO}_{6}\right)$ that is more appropriately treated as octahedral (compared to $\mathrm{NiO}_{5} \mathrm{~N}$ and $\mathrm{NiO}_{4} \mathrm{~N}_{2}$ ), thus decreasing the ZFS effects.

\section{Crystal Structures}

The structures of 3-6 have been determined by single crystal X-ray diffractometry and contrasted with $\mathbf{1}$ and $\mathbf{2}$. Salient metric parameters are collated in Table 3. Compounds $\mathbf{1 - 5}$ all contain the $\left\{\mathrm{Ni}_{2}\left(\mu_{2}-\right.\right.$ $\left.\left.\mathrm{O}_{2} \mathrm{C}^{t} \mathrm{Bu}\right)_{2}\left(\mu_{2}-\mathrm{OH}_{2}\right)\right\}$ core and vary only in the remaining two coordination sites at each nickel center that are incrementally changed from two pivalic acid groups to two pyridine ligands. The oxygen atom of the water molecule $\left(\mathrm{O}_{\mathrm{w}}\right)$ adopts a pseudo tetrahedral geometry. The water protons are aligned essentially parallel with each $\left\{\mathrm{Ni}\left(\mu_{2}-\right.\right.$ $\mathrm{O}_{2} \mathrm{C}^{\mathrm{t}} \mathrm{Bu}$ )Ni\} plane, which in turn lie at an angle of $\sim 80^{\circ}$ to each other. The hydrogen bond between the water molecule and the terminal pivalates is invariantly $\sim 2.5 \AA$ across the series. The nickel centers display only slight distortion from regular octahedral geometry, with an- gles between adjacent donors less than $5^{\circ}$ away from normal.

The effect of introducing pyridine ligands is assessed by monitoring the structural parameters of the $\left\{\mathrm{Ni}_{2}\left(\mu_{2}-\mathrm{OH}_{2}\right)\right\}$ unit (Table 3). The first substitution forming $\mathbf{2}$ and $\mathbf{4}$ is accompanied by an elongation of the $\mathrm{Ni}-\mathrm{O}_{\mathrm{w}}, \mathrm{Ni}-\mathrm{O}_{\mathrm{t}}$ and $\mathrm{Ni} \cdots \mathrm{Ni}$ distances by $\sim 0.07, \sim 0.06$ and $\sim 0.1$ $\AA$, respectively. In contrast, the $\mathrm{Ni}-\mathrm{O}$ bonds with the bridging and terminal pivalate ligands are essentially unchanged, with the terminal pivalates $c i s$ to the substitution site slightly more affected than those in the trans position. The addition of pyridine decreases the overlap between the metal and bridging water, lengthening the bond and slightly reducing the $\mathrm{Ni}-\mathrm{O}_{\mathrm{w}}-\mathrm{Ni}$ angle. It also weakens the bond with the remaining pivalic acid ligand, promoting a second substitution. The pyridines lie parallel to each other at distances typical for this ligand, and the additional methyl substituents in $\mathbf{4}$ have no bearing on the overall topology. The $\mathrm{Ni} \cdots \mathrm{Ni}$ distance exceeds $3.5 \AA$ and the $\mathrm{Ni}-\mathrm{O}_{\mathrm{w}}-\mathrm{Ni}$ angle expands to $\sim 115^{\circ}$ when all four pivalic acids are replaced by pyridine. If the $\mathrm{Ni}-\mathrm{O}_{\mathrm{w}}-\mathrm{Ni}$ angle were the dominant structural parameter, then we would expect compounds 1, 2 and $\mathbf{4}$ to be similar, and different from compounds $\mathbf{3}$ and $\mathbf{5}$.

Compound $\mathbf{6}$ is the nickel-doped magnesium analogue of compound 1, and was prepared so that we could directly measure the single-ion parameters of nickel in a near-identical environment, but in the absence of exchange coupling. The metric parameters are not expected to be identical between $\mathbf{1}$ and $\mathbf{6}$, given the significant difference in the metal radius between magnesium and nickel and the fact that the space group is slightly different ( $P b c a$ in $\mathbf{1}, P 2_{1} / n$ in $\mathbf{6}$ ), but they are actually quite close, and fall within the ranges set by $\mathbf{1}-\mathbf{5}$. We can therefore be confident that the parameters we obtain will be of relevance to the studies on the pure compounds.

\section{Magnetometry}

The temperature dependence of the product $\chi_{\mathrm{M}} T$ (where $\chi_{\mathrm{M}}=$ molar magnetic susceptibility and $T=$ temperature) for $\mathbf{1 - 5}$ are shown in Figure 3A. For all compounds, the room temperature $\chi_{\mathrm{M}} T$ values of around $2.5 \mathrm{~cm}^{3} \mathrm{~K}^{-1} \mathrm{~mol}^{-1}$ correspond well to the expected spin-only value for two uncoupled $S=1$ ions with $g_{\text {iso }}=2.2-2.3$. The value is constant until around $80 \mathrm{~K}$ for all compounds. At low temperature, 
Table 3. Salient Average Bond Distances $(\AA)$ and Angles $\left(^{\circ}\right)$ for 1-6

\begin{tabular}{lllllll} 
& $\mathbf{1}$ & $\mathbf{2}$ & $\mathbf{3}$ & $\mathbf{4}$ & $\mathbf{5}$ & $\mathbf{6}$ \\
\hline $\mathrm{Ni} \cdots \mathrm{Ni}$ & $3.361(1)$ & $3.465(2)$ & $3.5092(6)$ & $3.4760(7)$ & $3.511(1)$ & $3.462(1)$ \\
$\mathrm{Ni}-\mathrm{O}-\mathrm{Ni}$ & $111.2(1)$ & $110.7(3)$ & $115.8(1)$ & $110.6(1)$ & $114.7(2)$ & $112.5(1)$ \\
$\mathrm{Ni}-\mathrm{O}_{\mathrm{w} 1}$ & $2.037(2)$ & $2.106(4)$ & $2.075(3)$ & $2.087(2)$ & $2.085(5)$ & $2.080(2)$ \\
$\mathrm{Ni}-\mathrm{O}_{\mathrm{b} 2}$ & $2.018(3)$ & $1.992(5)$ & $2.045(3)$ & $2.034(2)$ & $2.061(5)$ & $2.032(2)$ \\
$\mathrm{Ni}-\mathrm{O}_{\mathrm{b} 3}$ & $2.032(3)$ & $1.983(5)$ & $2.027(3)$ & $1.998(2)$ & $2.023(5)$ & $2.063(2)$ \\
$\mathrm{Ni}-\mathrm{O}_{\mathrm{t}}$ & $2.053(3)$ & $2.069(5)$ & $2.069(3)$ & $2.070(2)$ & $2.058(5)$ & $2.092(2)$ \\
$\mathrm{Ni}-\mathrm{L}_{1}$ & $2.070(3)(\mathrm{O})$ & $2.142(5)(\mathrm{O})$ & $2.096(4)(\mathrm{N})$ & $2.118(2)(\mathrm{O})$ & $2.086(7)(\mathrm{N})$ & $2.073(2)$ \\
$\mathrm{Ni}-\mathrm{L}_{2}$ & $2.080(3)(\mathrm{O})$ & $2.095(7)(\mathrm{N})$ & $2.128(4)(\mathrm{N})$ & $2.089(3)(\mathrm{N})$ & $2.135(7)(\mathrm{N})$ & $2.097(2)$ \\
\hline
\end{tabular}

Values calculated using $\left(\sum x_{\mathrm{i}} / n\right)$, where $x$ is the bond metric and $n$ is the number of values averaged. ' $w$ ' denotes the oxygen of the bridging water group, ' $b$ ' the bridging pivalate, ' $t$ ' the terminal pivalate, and ' $\mathrm{L}$ ' represents the atoms at the labile terminal positions. 1, 2, and 3 denote pairs trans to each other.

the plot follows a markedly different profile for $\mathbf{1}$ and $\mathbf{4}$, which rise, suggesting ferromagnetic coupling, compared to $\mathbf{2}, \mathbf{3}$, and $\mathbf{5}$, which exhibit a sharp drop at low temperatures. It is tempting to attribute this drop to an antiferromagnetic exchange (indeed, this was done by others $^{29}$ for compound 2), but this neglects the effect of the zero-field splitting (ZFS), or at least assumes that it is much smaller than the exchange. To illustrate this point, we modeled the susceptibility alone for 2 and obtained a value for $J$ of $-0.5 \mathrm{~cm}^{-1}$ (using the $-2 J$ convention). In reality, the ZFS can easily be on the order of the exchange interaction in compounds containing octahedral nickel(II), and may even be significantly larger. ${ }^{30}$

In compound 1 , the upturn in the susceptibility below $50 \mathrm{~K}$ culminating in a $\chi_{\mathrm{M}} T$ value of $3.9 \mathrm{~cm}^{3} \mathrm{~K}^{-1} \mathrm{~mol}^{-1}$ at $2.5 \mathrm{~K}$, before a sharp downturn due to ZFS is consistent with an $S=2$ ground state of two ferromagnetically coupled nickel(II) ions. We rule out the possibility of weak intermolecular interactions as the cause of this downturn by noting that in compounds $\mathbf{1}-\mathbf{5}$, the intermolecular $\mathrm{Ni} \cdots \mathrm{Ni}$ distances are never below $\sim 9 \AA$. Compound $\mathbf{4}$ also exhibits an upturn in $\chi_{\mathrm{M}} T$ upon cooling below $\sim 40 \mathrm{~K}$ that is likely due to a ferromagnetic interaction, albeit weaker than in 1, with ZFS again resulting in the onset of a sharp downturn $(\sim 10 \mathrm{~K})$ that prevents the susceptibility reaching the value for a pure $S=2$ state.

The field-dependent magnetization curves are given in Figure 3B. Compound 1 exhibits a sharp rise at low fields, with the $2 \mathrm{~K}$ data reaching saturation above $5 \mathrm{~T}$. In contrast, compound $\mathbf{2}$ exhibits a very shallow rise that fails to reach saturation even at $7 \mathrm{~T}$. Compounds 3-5 exhibit behaviour that falls in between these two extremes.

For all five compounds, we begin by fitting the temperaturedependent susceptibility alongside the field-dependent magnetization using the spin Hamiltonian given in Equation 2. In this model, the single-ion anisotropy of the two nickel ions are assumed to be axial $\left(D_{\mathrm{xx}}=D_{\mathrm{yy}}=-D / 3\right.$ and $\left.D_{\mathrm{zz}}=2 D / 3\right)$ and also equivalent, even though this is only strictly true for the symmetry related ions in $\mathbf{2}$ and $\mathbf{4}$, and the exchange is treated as isotropic.

$$
\hat{H}=g \beta\left(\hat{S}_{1}+\hat{S}_{2}\right) \cdot \vec{H}+\hat{S}_{1} \cdot \boldsymbol{D} \cdot \hat{S}_{1}+\hat{S}_{2} \cdot \boldsymbol{D} \cdot \hat{S}_{2}-2 J \hat{S}_{1} \cdot \hat{S}_{2}
$$

Good fits to the data can be obtained using this model, but are ambiguous with regards to the sign of the axial ZFS parameter, $D$, and are unable to offer a conclusive measure of the exchange interaction, which appears to be smaller than the ZFS in 2-4. In fact, the isotropic exchange parameter, $J$, can be varied over a range of values (keeping the fitted $D$ and $g_{\text {iso }}$ values fixed) before adversely affecting the "goodness" of the simulations. These ranges for the value of $J$ (in units of $\mathrm{cm}^{-1}$ ) are: $\mathbf{1}: 2.30$ to $2.90,2: 0.10$ to $0.35, \mathbf{3}:-0.05$ to -0.20 4: 0.55 to $0.85,5:-0.25$ to -0.45 .

As a result, it is impossible to deduce the exchange (and, importantly, to compare values across the series) from fitting the magnetic data alone; further data are clearly required to understand the magnetic behaviour of these simple compounds unambigiously. Here, the additional data are EPR spectroscopy at $331 \mathrm{GHz}$ on pure and doped samples, and CASSCF calculations to yield estimates of the $g$-values and anisotropy parameters for single ion sites.

INS data for compound $\mathbf{1}$ were actually collected over a decade ago $;{ }^{19}$ INS and magnetic susceptibility were used to model the exchange and ZFS parameters, but the poor quality of the INS data meant that the rhombic term of the zero-field splitting tensor, $E$, was neglected and only isotropic exchange was employed, a scheme that we will show is inappropriate for these systems (vide infra). The INS data are reproduced in the Supporting Information and are consistent with the model we arrive at from the present EPR studies.

\section{Single Ion Anisotropy: EPR Spectroscopy}

To determine the single ion parameters $(g, D$, and $E)$ in $\mathbf{1}$ without the added complexity of exchange coupling, we synthesized a diamagnetic magnesium analogue doped with 5\% nickel (6). At this doping level, the amount of pure $\mathrm{Ni}-\mathrm{Ni}$ molecule is expected to be virtually undetectable compared to $\mathrm{Mg}-\mathrm{Mg}$ (diamagnetic) and $\mathrm{Mg}-\mathrm{Ni}$ molecules, and thus the spectrum should be that of the individual nickel ions (i.e. the exchange coupling interaction is effectively turned off). The powder HFEPR spectrum (Figure 4 and Figure S3) reveals sharp transitions localized at 5.0-5.5 T, with broader features over the range 8.5-13.5 T, and resembles the spectrum expected of an $S=1$ ion with a rhombic ZFS.

These spectra can be modeled as two non-equivalent nickel sites with the following parameters: $g_{\mathrm{x} 1}=g_{\mathrm{y} 1}=2.32, g_{\mathrm{z} 1}=2.25, g_{\mathrm{x} 2}=g_{\mathrm{y} 2}$ $=2.25, g_{\mathrm{z} 2}=2.19, D_{1}=+1.6 \mathrm{~cm}^{-1}, E_{1}=+0.35 \mathrm{~cm}^{-1}, D_{2}=+1.1 \mathrm{~cm}^{-1}$, $E_{2}=+0.20 \mathrm{~cm}^{-1}$. Reassuringly, the simulation recreates the appearance of a pair of features at around $11.5 \mathrm{~T}$ (marked with an asterisk) upon warming from 5 to $15 \mathrm{~K}$, which can be attributed to transitions into the $m_{\mathrm{S}}=1$ state from the increasingly thermally populated $m_{\mathrm{S}}=$ 0 state.

\section{Single Ion Anisotropy: Computational Modeling}

Taking inspiration from previous success with cobalt analogues of these complexes, ${ }^{31}$ compounds $\mathbf{1}-\mathbf{5}$ were modeled using complete active space calculations to generate estimates for the anisotropic $g$ - 

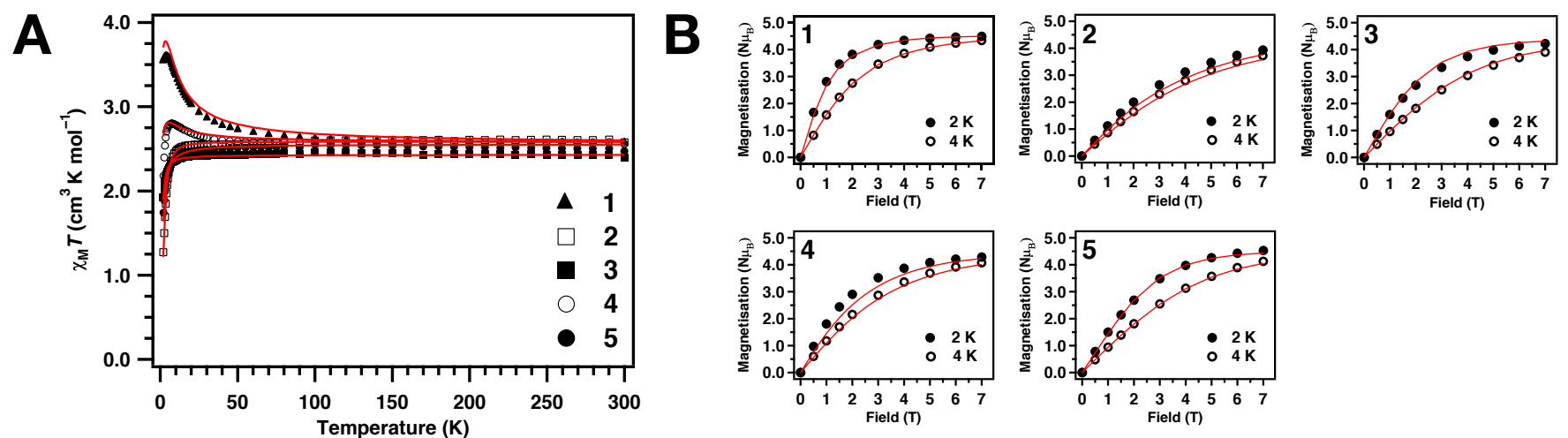

Figure 3. (A) Overlay of the temperature dependence of the magnetic susceptibility recorded on powders of 1-5 under a static field of $0.1 \mathrm{~T}$. (B) Field-dependent magnetization of compounds 1-5 measured at 2 and $4 \mathrm{~K}$. Solid lines in all graphs represent simulations using the parameters in Table 6.

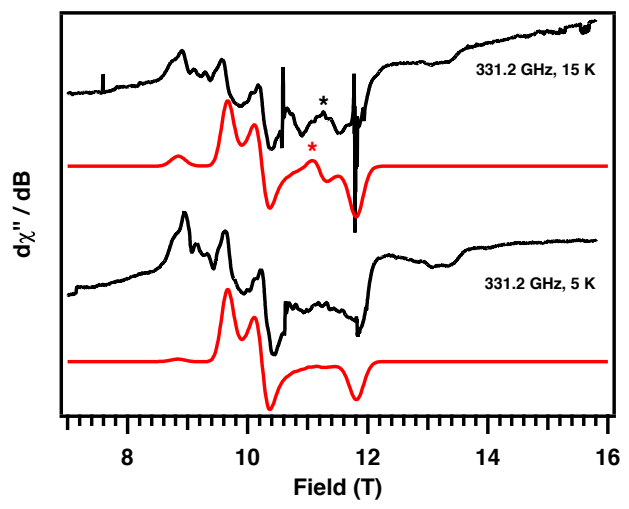

Figure 4. Powder electron paramagnetic resonance spectra of 6 measured at $331.2 \mathrm{GHz}$ at 5 and $15 \mathrm{~K}$, with the simulation shown in red. $g_{\mathrm{x} 1}=g_{\mathrm{y} 1}=2.32, g_{\mathrm{z} 1}=2.25, g_{\mathrm{x} 2}=g_{\mathrm{y} 2}=2.25$, $g_{\mathrm{z} 2}=2.19, D_{1}=+1.6 \mathrm{~cm}^{-1}, E_{1}=+0.35 \mathrm{~cm}^{-1}, D_{2}=+1.1$ $\mathrm{cm}^{-1}, E_{2}=+0.20 \mathrm{~cm}^{-1}$. Asterisks indicate the appearance of a pair of features upon warming to $15 \mathrm{~K}$ that is recreated in the simulated spectrum.

values and individual site ZFS parameters. Compounds 2 and $\mathbf{4}$ possess nickel(II) sites that are related by symmetry (2-fold rotation), while compounds $\mathbf{1}, \mathbf{3}$, and $\mathbf{5}$, have independent sites, with compound 3 having not two but four independent nickel sites (two molecules per asymmetric unit). In all cases, the nickel site that is not the focus of the calculation is replaced by a diamagnetic zinc(II) ion. The active space was chosen as the five $3 d$ orbitals of the nickel(II) ion, where all $10 S=1$ and $15 S=0$ configuration state functions were calculated and mixed by spin-orbit coupling. From these calculations, the $g_{\mathrm{x}}, g_{\mathrm{y}}$, $g_{\mathrm{z}}, D$, and $E$ values for the $S=1$ ground multiplet can be extracted (Table 4). Expanding the active space to include the $4 d$ orbitals of the nickel(II) ion (the so-called "double shell effect") proved only to affect the results in a minor fashion (Table 5), and therefore this was not investigated for the remaining complexes. It is also possible to extract the orientations of the $\boldsymbol{D}$ tensor and the $\boldsymbol{g}$ matrix (see Supporting Information).

The calculated parameters for $\mathbf{1}$ and the parameters obtained from simulations of $\mathbf{6}$ differ, chiefly in the magnitude of $D$ ( $a b$ initio: $+4.4 /+3.2 \mathrm{~cm}^{-1}$; experimental: $\left.+1.6 /+1.1 \mathrm{~cm}^{-1}\right)$. The observed axiality of $g$ is reproduced, and is of the same sense $\left(g_{\mathrm{z}}<g_{\mathrm{x}}=g_{\mathrm{y}}\right)$,
Table 4. Calculated $g, D$ and $E$ Parameters for the $S=1$ Ground State with 8 Electrons in 5 Orbitals, for 1-5

\begin{tabular}{llllll} 
Compound, Site & $g_{\mathrm{x}}$ & $g_{\mathrm{y}}$ & $g_{\mathrm{z}}$ & $D\left(\mathrm{~cm}^{-1}\right)$ & $E\left(\mathrm{~cm}^{-1}\right)$ \\
\hline $\mathbf{1}, \mathrm{Ni} 1$ & 2.34 & 2.34 & 2.31 & +4.4 & -0.3 \\
$\mathbf{1}, \mathrm{Ni} 2$ & 2.34 & 2.33 & 2.31 & +3.2 & -0.2 \\
$\mathbf{2}, \mathrm{Ni} 1$ & 2.35 & 2.33 & 2.28 & +8.7 & -1.3 \\
$\mathbf{3}, \mathrm{Ni} 1$ & 2.29 & 2.30 & 2.31 & -2.4 & +0.5 \\
$\mathbf{3}, \mathrm{Ni} 2$ & 2.28 & 2.29 & 2.31 & -3.0 & +0.7 \\
$\mathbf{3}, \mathrm{Ni} 3$ & 2.31 & 2.30 & 2.29 & -1.7 & +0.5 \\
$\mathbf{3}, \mathrm{Ni} 4$ & 2.29 & 2.29 & 2.28 & +2.0 & -0.4 \\
$\mathbf{4}, \mathrm{Ni} 1$ & 2.34 & 2.33 & 2.28 & +6.4 & -1.3 \\
$\mathbf{5}, \mathrm{Ni} 1$ & 2.31 & 2.30 & 2.29 & +3.0 & -0.9 \\
$\mathbf{5}, \mathrm{Ni} 2$ & 2.30 & 2.30 & 2.28 & +2.5 & -0.6 \\
\hline
\end{tabular}

Table 5. Calculated $g, D$ and $E$ Parameters for the $S=1$ Ground State with 8 Electrons in 10 Orbitals, for $\mathbf{1}$

\begin{tabular}{llllll} 
Compound, Site & $g_{\mathrm{x}}$ & $g_{\mathrm{y}}$ & $g_{\mathrm{z}}$ & $D\left(\mathrm{~cm}^{-1}\right)$ & $E\left(\mathrm{~cm}^{-1}\right)$ \\
\hline $\mathbf{1}, \mathrm{Ni} 1$ & 2.32 & 2.32 & 2.29 & +4.0 & -0.3 \\
$\mathbf{1}, \mathrm{Ni} 2$ & 2.31 & 2.31 & 2.29 & +3.0 & -0.2 \\
\hline
\end{tabular}

which is consistent with a positive $D .{ }^{32,33}$ What is most noticeable about the calculated parameters is the extreme sensitivity of $D$ to the nickel coordination environment. This parameter varies from +8.7 to $-3.0 \mathrm{~cm}^{-1}$ with only minor changes in coordination sphere. This covers as wide an energy range as the observed exchange interactions in nickel compounds. ${ }^{9,18}$ The experimental $D$-value for the isolated nickel(II) ions in 6 suggests that the calculated values are somewhat overestimated. The calculated $g$-values are also much less sensitive to coordination environment than is found experimentally.

\section{Di-nickel Compounds: EPR Spectroscopy}

Compounds 1-5 were first measured in the powder state at lower frequencies (see Supporting Information). These spectra are extremely difficult to interpret due to a very limited number of transitions falling within the available magnetic field range. Such complexity often arises in compounds where a significant ZFS (which is typical for nickel) is acting on weakly coupled, non-Kramers ions. As an example we show the Q-band spectrum of compound 1 (Figure 5). Examples 


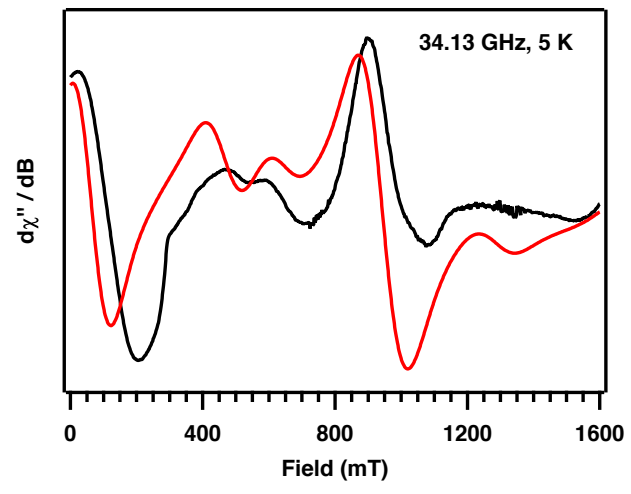

Figure 5. Q-band EPR of 1 measured in the powder state. Red trace is a simulation using the parameters in Table 6.

for the other compounds are given in the Supporting Information.

To allow for the large ZFS we need to move to frequencies where hv is larger than the ZFS. We therefore collected powder spectra (Figure 6) at a much higher frequency $(331.2 \mathrm{GHz})$ and over a much larger field range (0-16 T). Although the definition of the features is greatly improved, the spectra are still remarkably complicated for such simple compounds, and the variation between spectra is considerable.

Compounds 1, 3 and 5 exhibit their most intense features between 9-14 T, with effectively no transitions at lower fields. Although compounds 2 and 4 display transitions in this same region, they also exhibit features at lower fields, between 1-4 T, that are of a much higher intensity. These low-field transitions are a signature of signifcantly larger ZFS terms in these examples.

The combination of the doped study and computational work gives us a guide to the single ion parameters. To interpret the complex spectra of 1-5 we have used the spin Hamiltonian given in Equation 3 , where now $D_{\mathrm{xx}}=-D / 3+E, D_{\mathrm{yy}}=-D / 3-E$ and $D_{\mathrm{zz}}=2 D / 3$.

$$
\hat{H}=\beta\left(\hat{S}_{1} \cdot \boldsymbol{g}_{1}+\hat{S}_{2} \boldsymbol{g}_{2}\right) \cdot \vec{H}+\hat{S}_{1} \cdot \boldsymbol{D}_{\mathbf{1}} \cdot \hat{S}_{1}+\hat{S}_{2} \cdot \boldsymbol{D}_{\mathbf{2}} \cdot \hat{S}_{2}-2 J \hat{S}_{1} \cdot \hat{S}_{2}
$$

This is almost identical to the Hamiltonian used to fit the magnetic data, except that we have introduced rhombic ZFS $(E)$ terms and also the possibility for anisotropic exchange. In all cases, the reference frames for the $\boldsymbol{g}_{\mathrm{i}}$ matrix and $\boldsymbol{D}_{\mathrm{i}}$ tensors are coincident for a given metal site, however the reference frames may differ between different nickel sites. Aditionally, $J$ is always fixed in the global reference frame. We initially chose to keep $\boldsymbol{g}_{\mathrm{i}}, \boldsymbol{D}_{\mathrm{i}}$ and $J$ coincident in all compounds to reduce the number of parameters, and neglected the fact that the metal centers in $\mathbf{3}$ and $\mathbf{5}$ were crystallographically non-equivalent (i.e. the parameters for all sites were taken as identical, assuming a pseudo symmetry).

We started by simultaneously fitting the $\chi_{\mathrm{M}} T(T)$ and $M(H, T)$ data to Equation 2 to obtain initial values of $J$ and $D_{\mathrm{i}}$, before introducing these parameters into Equation 3 to calculate HFEPR spectra, now introducing $E_{\mathrm{i}}$, and refining $J$ and $D_{\mathrm{i}}$. As a next step we introduced Euler angles relating the $D_{\mathrm{i}}$ tensors (assuming they are related by a two-fold axis as in $\mathbf{2}$ and 4): these angles were fixed from CASSCF calculations (see Supporting Information). This only made significant improvements in-and hence were only retained for-compounds 2 and $\mathbf{4}$, which we assume is because of their much larger $D_{\mathrm{i}}$ values (and possibly because they have true crystallographic equivalence of the centers). The final parameters (Table 6) were then used to recalculate

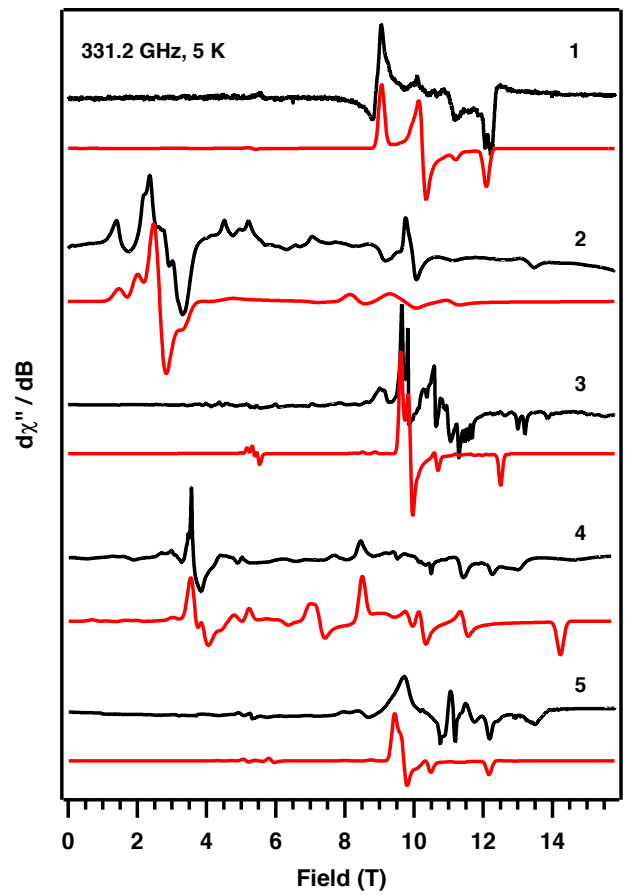

Figure 6. Solid-state high field EPR $(331.2 \mathrm{GHz})$ spectra of 1-5. Experimental traces are in black, with simulations using the parameters in Table 6 plotted in red.

$\chi_{\mathrm{M}} T(T)$ and $M(H, T)$ (Figure 3). For compound 1, where we had the doped materials available, the single ion parameters were fixed from the doping study. Because we have more information for this complex (hence fewer free variables), we investigated the effect of a small anisotropic component to $J$ (on the order of the dipolar interaction) and found this gave an improvement to the calculated EPR spectra. For 2-5, where we do not have the doped analogues, $J$ was held as isotropic.

The final parameter sets used to generate all of the simulations shown in this paper (including the magnetic data) are given in Table 6. The fits to the observed HFEPR spectra are remarkably good for $\mathbf{1}$ and the main features of 2-4 are also simulated. However, in each case additional experimental features are observed that do not arise from this simple model. The predicted trend in the magnitude of $D$ from ab initio calculations $(\mathbf{2}, \mathbf{4}>\mathbf{1}, \mathbf{3}, \mathbf{5})$ is supported, but the calculated values themselves do not give good simulations. A key result of this study is that the low field features observed for $\mathbf{2}$ and $\mathbf{4}$ can only be reproduced with $|D|>5 \mathrm{~cm}^{-1}$.

In 2-5, there is no obvious benefit to using anisotropic $g$-values, and so isotropic $g$-values are retained. The small anisotropy in the $g$-values is predicted by $a b$ initio methods, and the magnitude of the $g$-values from both experimental and $a b$ initio methods are within the expected range for nickel(II) ions, albeit generally overestimated in the latter.

Experimentally, the sign of $D$ is positive for all compounds, which is in general agreement with ab initio methods, which predict a positive $D$ in all compounds except for $\mathbf{3}$, where in fact three of the nonequivalent centers are predicted to be negative, and the remaining one positive.

Assessing the simulation parameters given in Table 6 alongside the structural parameters in Table 3 allows us to comment on a number 
Table 6. Electronic Parameters Used in the Global Simulations of 1-5

\begin{tabular}{llllll} 
& $\mathbf{1}$ & $\mathbf{2}$ & $\mathbf{3}$ & $\mathbf{4}$ & $\mathbf{5}$ \\
\hline$g_{\mathrm{xx}}, g_{\mathrm{yy}}$ & $2.32 / 2.25$ & 2.24 & 2.20 & 2.26 & 2.26 \\
$g_{\mathrm{zz}}$ & $2.25 / 2.19$ & 2.24 & 2.20 & 2.26 & 2.26 \\
$D\left(\mathrm{~cm}^{-1}\right)$ & $+1.60 /+1.10$ & +7.40 & +2.10 & +5.40 & +1.80 \\
$E\left(\mathrm{~cm}^{-1}\right)$ & $+0.35 /+0.20$ & +2.45 & +0.10 & +1.40 & +0.10 \\
$J_{\mathrm{xx}}, J_{\mathrm{zz}}\left(\mathrm{cm}^{-1}\right)$ & +2.40 & +0.35 & -0.1 & +0.70 & -0.3 \\
$J_{\mathrm{yy}}\left(\mathrm{cm}^{-1}\right)$ & +2.55 & +0.35 & -0.1 & +0.70 & -0.3 \\
$R\left({ }^{\circ}\right)^{a}$ & $0,0,0$ & $+109,-88.5,-71.0$ & $0,0,0$ & $+70.6,+102,-109$ & $0,0,0$ \\
\hline
\end{tabular}

${ }^{a}$ Euler rotations of one nickel site in relation to the other in the $Z Y^{\prime} Z^{\prime \prime}$ convention.

of possible correlations. Firstly, the magnitude of the axial parameter, $D$, is significantly larger in $\mathbf{2}$ and $\mathbf{4}$. This can be explained by the presence of a well-defined axis along the nitrogen atom in the $\mathrm{NiNO}_{5}$ coordination sphere for these compounds. The addition of a further nitrogen atom in $\mathbf{3}$ and $\mathbf{5}$, yielding $\mathrm{NiN}_{2} \mathrm{O}_{4}$ with oxygen atoms cis to each other, is accompanied by a reduction in $D$, as there is no longer a unique metal-donor atom direction. This magneto-structural correlation is very clear. The dramatic difference in the measured EPR spectra of $\mathbf{1}$ compared with those of $\mathbf{2}$ and $\mathbf{4}$ is then due to the much larger change in $D$ between the complexes. Secondly, the exchange is ferromagnetic in nature for 1,2 and 4 , which have the smallest $\mathrm{Ni}-\mathrm{O}_{\mathrm{w}}-\mathrm{Ni}$ angles of the series. It is worth noting that despite the ferromagnetic exchange observed in $\mathbf{2}$, the product $\chi_{\mathrm{M}} T$ falls at low temperature, which is due to $D$ being twenty times as large as $J$.

\section{Conclusion}

Detailed magnetic and EPR studies carried out on five closely-related di-nickel compounds, and on a doped diamagnetic analogue of the parent compound, have shown that incredibly rich and diverse data can be obtained from seemingly simple compounds. At first glance, there is no simple correlation between structure and magnetic or spectroscopic behaviour, e.g. compounds $\mathbf{1}$ and $\mathbf{2}$ have very similar $\mathrm{Ni}-\mathrm{O}_{\mathrm{w}}-\mathrm{Ni}$ angles, but in the former case variable temperature susceptibility measurements show an upturn in $\chi_{\mathrm{M}} T$ at low temperature, and in the latter a downturn.

However, detailed analysis shows that in these five simple compounds there are two correlations. The major correlation is between the axial zero-field splitting parameter, $D$, and the coordination geometry; where there is a single unique axis, due to the presence of a $\mathrm{N}$-donor in $\mathrm{NiO}_{5} \mathrm{~N}$ donor set, the $D$-value is around three times larger than in a $\mathrm{NiO}_{6}$ donor set, or in a cis $\mathrm{NiO}_{4} \mathrm{~N}_{2}$ donor set. The measured thermodynamic and spectroscopic properties vary most due to this correlation. When this is allowed for, we find that the correlation ${ }^{9,18}$ between bridging angle and the sign of the magnetic exchange interaction still appears to be present. This supports the hypothesis that the dominant superexchange pathway in these compounds is via the bridging water molecule. ${ }^{31}$

Magneto-structural correlations continue to appear, but these should be treated with considerable scepticism unless one Hamiltonian is used to simulate all the data. For example, we could easily have simulated the magnetic susceptibity data of 1-5 to a simple isotropic Zeeman plus exchange Hamiltonian and described the trends in $J$ with respect to structure. This would have had no physical meaning, because modeling the magnetization data (requiring local anisotropy terms that are larger than $J$ ) shows that such a Hamiltonian is not only insufficient but that the $J$-values so determined are wrong (even giving the wrong sign). This would not be helped by fitting the magnetization data to a second, different Hamiltonian (often based on a giant spin approximation), to determine global zero-field splitting parameters, as this is only appropriate when $J \gg D_{\mathrm{i}}$. Hence, care needs to be taken in attempting to correlate spin Hamiltonian parameters to structure when the anisotropy terms are larger than or comparable to the exchange, ${ }^{34}$ and this requires that the data are treated with a single Hamiltonian. ${ }^{35}$ Any meaningful model should fit both variable temperature susceptibility and variable field magnetization, and other spectroscopic data where available.

\section{Acknowledgements}

This research was funded by the EPSRC (UK) and R.E.P.W. holds a Royal Society Wolfson Research Merit Award. J.P.S.W. thanks the North West Nanoscience DTC for a PhD studentship. N.F.C. thanks the University of Manchester for a President's Doctoral Scholarship. We thank the EPSRC UK National Electron Paramagnetic Resonance Service at the University of Manchester.

\section{Supporting Information Available}

Infrared spectra for $\mathbf{1 - 5}$, full range HFEPR spectra for $\mathbf{6}$, low temperature Q-band EPR spectra for 2-5, Euler rotations of $g / D$ from CASSCF calculations, INS spectrum of $\mathbf{1}$ using data from Ref. 19. This material is available free of charge via the Internet at http://pubs.acs.org.

\section{References}

(1) Leuenberger, M. N.; Loss, D. Nature, 2001, 410, 789-793.

(2) Sharples, J. W.; Collison, D. Polyhedron, 2013, 54, 91-103.

(3) (a) Ohba, S; Kato, M.; Tokii, T.; Muto, Y; Steward, O. W. Mol. Cryst. Liq. Cryst., 1993, 233, 335-344; (b) Ribas, J.; Escuer, A.; Monfort, M.; Vincente, R.; Cortes, R.; Lezama, L.; Rojo, T. Coord. Chem. Rev., 1999, 193, 1027-1068; (c) Ruiz, E.; Cano, J.; Alvarez, S.; Alemany, P. J. Am. Chem. Soc., 1998, 120, 11122-11129; (d) Rodriguez-Fortea, A.; Alemany, P.; Alvarez, S.; Ruiz, E. Chem. Eur. J., 2001, 7, 627-637; Mialane, P.; Duboc, C.; Marrot, J. Riviere, E.; Dolbecq, A.; Secheresse, F. Chem. Eur. J., 2006, 12, 1950-1959; (e) Thompson, L.K.; Mandal, S. K.; Tandon, S. S.;Brisdon, J. N.; Park, M. K. Inorg. Chem., 1996, 35, 3117-3125.

(4) (a) Escuer, A.; Aromi, G. Eur. J. Inorg. Chem., 2006, 4721-4736; (b) Gómez, V; Corbella, M.; Roubeau, O.; Teat, S., J. Dalton Trans., 2011, 40, 11968-11975. 
(5) Gorun, S. M.; Lippard, S. J. Inorg. Chem., 1991, 30, 1626-1630. (6) (a) Gregoli, L.; Danieli, C.; Bara, A.-L., Neugebauer, P.; Pellegrino, G.; Poneti, G.; Sessoli, R.; Cornia, A. Chem. Eur. J., 2009, 15, 6456-6467; (b) Maganas, D.; Krzystek, J.; Ferentinos, E.; Whyte, A. M.; Robertson, N.; Psycharis, V.; Terzis, A.; Neese, F.; Kyritsis, P. Inorg. Chem., 2012, 51, 7218-7231; (c) Maurice, R.; de Graaf, C.; Guihery, N. J. Chem. Phys., 2010, 133, 084307; (d) Barra, A.-L.; Caneschi, A.; Cornia, A.; Gatteschi, D.; Gorini, L.; Heiniger, L. P.; Sessoli, R.; Sorace, L. J. Am. Chem. Soc., 2007, 129, 10754-10762.

(7) Crawford, V. H.; Richardson, H. W.; Wasson, J. R.; Hodgson, D. J.; Hatfield, W. E. Inorg. Chem., 1976, 15, 2107-2110.

(8) Weihe, H.; Güdel, H. U. J. Am. Chem. Soc., 1997, 119 6539-6543.

(9) Halcrow, M. A.; Sun J.-S.; Huffman, J. C.; Christou, G. Inorg. Chem., 1995, 34, 4167-4177.

(10) Cañada-Vilalta, C.; O’Brien, T. A.; Brechin, E. K.; Pink, M.; Davidson, E. R.; Christou, G. Inorg. Chem., 2004, 43, 5505-5521.

(11) Basler, R.; Boskovic, C. ; Chaboussant, G.; Güdel, H. U.; Murrie, M.; Ochsenbein, S. T.; Sieber, A. ChemPhysChem, 2003, 4, 910-926, and references therein.

(12) (a) Piligkos, S.; Bill, E.; Collison, D.; McInnes, E. J. L.; Timco, G. A.; Weihe, H; Winpenny, R. E. P.; Neese, F. J. Amer. Chem. Soc., 2007, 129, 760-761; (b) Piligkos, S.; Weihe, H; Bill, E.;Neese, F.; El Mkami, H.; Smith, G. M.; Collison, D.; Rajamaran, G.; Timco, G. A.; Winpenny, R. E. P.; McInnes, E. J. L. Chem. Eur. J., 2009, 15, 3152-3167.

(13) Magee, S. A.; Sproules, S.; Barra, A.-L.; Timco, G. A.; Chilton, N. F.; Collison, D.; Winpenny, R. E. P.; McInnes, E. J. L. Angew. Chem. Int. Ed., 2014, 53, 5310-5313.

(14) Ako, A. M.; Hewitt, I. J.; Mereacre, V.; Clérac, R.; Wernsdorfer, W.; Anson, C. E.; Powell, A. K. Angew. Chem. Int. Ed., 2006, 45, 4926-4929.

(15) See for example: Blagg, R. J.; Ungur, L.; Tuna, F.; Speak, J.; Comar, P.; Collison, D.; Wernsodrfer, W.; McInnes, E. J. L.; Chibotaru, L. F.; Winpenny, R. E. P. Nature Chem., 2013, 5, 673-678.

(16) Zadrozny, J. M.; Xiao, D. J.; Atanasov, M.; Long, G. J.; Grandjean, F.; Neese, F.; Long, J. R. Nature Chem., 2013, 5, 577-581.

(17) Wilson, A.; Lawrence, J.; Yang E.-C.; Nakano, M.; Hendrickson, D. N.; Hill, S. Phys Rev. B, 2006, 74, 140403.

(18) (a) Nanda, K. K.; Thompson, L. K.; Bridson, J. N.; Nag, K. J. Chem. Soc., Chem. Commun., 1992, 1337-1338. (b) Thompson, L. K.; Brisdon, J. N.; Nag, K., J. Chem. Soc., Chem. Commun., 1994, 1337-1338.

(19) Chaboussant, G; Basler, R.; Güdel, H-U.; Ochsenbein, S; Parkin, A.; Parsons, S.; Rajaraman, G.; Sieber, A.; Smith, A. A.; Timco, G. A.; Winpenny, R. E. P. Dalton Trans., 2004, 17, 2758-2766.

(20) Eremenko, I. L.; Nefedov, S. E.; Sidorov, A. A.; Moiseev, I. I. Russ. Chem. B+, 1999, 48, 405-416.

(21) Sheldrick, G. M. Acta Cryst., 2008, 64, 112-122.

(22) Chilton, N. F.; Anderson, R. P.; Turner, L. D.; Soncini, A.; Murray, K. S. J. Comput. Chem., 2013, 34, 1164-1175.

(23) Barra, A. L.; Brunel, L. C.; Robert, J. B. Chem. Phys. Lett., 1990, 165, 107-109.

(24) Stoll, S.; Schweiger, A. J. Magn. Reson., 2006, 178(1), 42-55.

(25) (a) Karlström, G.; Lindh, R.; Malmqvist, P.-Å.; Roos, B. O.; Ryde, U.; Veryazov, V.; Widmark, P.-O.; Cossi, M.; Schimmelpfennig, B.; Neogrady, P.; Seijo, L. Comput. Mater. Sci., 2003, 28, 222-239. (b) Veryazov, V.; Widmark, P.; Serrano-Andrés, L.; Lindh, R.; Roos, B. O. Int. J. Quantum Chem., 2004, 100, 626-635. (c)
Aquilante, F.; De Vico, L.; Ferré, N.; Ghigo, G.; Malmqvist, P.; Neogrády, P.; Pedersen, T. B.; Pitoňák, M.; Reiher, M.; Roos, B. O.; Serrano-Andrés, L.; Urban, M.; Veryazov, V.; Lindh R. J. Comput. Chem., 2010, 31, 224-247.

(26) Rajaraman, G.; Christensen, K. E.; Larsen, F. K.; Timco, G. A.; Winpenny, R. E. P. Chem. Commun., 2005, 3053-3055.

(27) Aromí, G.; Batsanov, A. S.; Christian, P.; Helliwell, M.; Parkin, A.; Parsons, S.; Smith, A. A.; Timco, G. A.; Winpenny, R. E. P. Chem. Eur. J., 2003, 9, 5142-5161.

(28) Cotton, F. A.; Wilkinson, G. Chemistry of the Transition Elements. Advanced Inorganic Chemistry, $4^{\text {th }}$ ed.; John Wiley \& Sons: New York, 1980; p 786 f.

(29) Eremenko, I. L.; Golubnichaya, M. A.; Nefedov, S. E.; Sidorov, A. A.; Golovaneva, I. F.; Burkov, V. I.; Ellert, O. G.; Novotortsev, V. M.; Eremenko, L. T.; Sousa, A.; Bermejo, M. R. Russ. Chem. B., 1998, 47, 704-718.

(30) Titiš, J.; Boča, R. Inorg. Chem., 2010, 49, 3971-3973.

(31) Boeer, A. B.; Barra, A.-L.; Chibotaru, L. F.; Collison, D.; McInnes, E. J. L.; Mole, R. A.; Simeoni, G. G.; Timco, G. A.; Ungur, L.; Unruh, T.; Winpenny, R. E. P. Angew. Chem. Int. Ed., 2011, 50, 4007-4011.

(32) Mabbs, F. E.; Collison, D. Electron Paramagnetic Resonance of d Transition Metal Compounds, Elsevier, Amsterdam, 1992, p 482.

(33) Atanasov, M.; Comba, P.; Helmle, S.; Müller, D.; Neese, F. Inorg. Chem., 2012, 51, 12324-12335.

(34) Inglis, R.; Jones, L. F.; Milios, C. J.; Datta, S.; Collins, A.; Parsons, S.; Wernsdorfer, W.; Hill, S.; Perlepes, S. P.; Piligkos, S.; Brechin, E. K. Dalton Trans., 2009, 18, 3403-3412.

(35) Herchel, R.; Boča, R.; Krzystek, J.; Ozarowski, A.; Durán, M; van Slageren, J. J. Am. Chem. Soc., 2007, 129(34), 10306-10307. 